\title{
High Irradiance Laser Ionization Mass Spectrometry for Direct Speciation of Iron Oxides
}

\author{
Bin Yan, ${ }^{\mathrm{a}}$ Lingfeng Li, ${ }^{\mathrm{a}}$ Quan Yu, ${ }^{\mathrm{a}}$ Wei Hang, ${ }^{\mathrm{a}} \mathrm{b}$ Jian $\mathrm{He},{ }^{\mathrm{c}}$ and \\ Benli Huang ${ }^{a}$ \\ ${ }^{a}$ Department of Chemistry, College of Chemistry and Chemical Engineering, Xiamen University, \\ Xiamen, China \\ b State Key Laboratory of Marine Environmental Science, Xiamen University, Xiamen, China \\ ${ }^{\mathrm{c}}$ Department of Mechanical and Electrical Engineering, Xiamen University, Xiamen, China
}

A novel method has been developed that allows the direct speciation analysis of iron oxides based on a modified laser ionization orthogonal time-of-flight mass spectrometer. Time resolved mass spectra were acquired for the investigation of elemental ions and oxide ions generated by a laser ionization source. Speciation methodologies, including the identification of characteristic ions and the use of ion abundance ratios were evaluated for the differentiation of the oxides. The influence of operating parameters on the distribution of cluster ions was investigated, and their mechanism of formation discussed. (J Am Soc Mass Spectrom 2010, 21, 1227-1234) (C) 2010 American Society for Mass Spectrometry

$\mathrm{T}$ Traditionally, mineral analysis focuses on the quantitative determination of the principle composition and impurity elements. Usually, samples are dissolved and analyzed by related instrumentation methods, such as atomic emission, absorption, fluorescence spectroscopy (AES, AAS, AFS) [1], and plasma mass spectrometry (MS) [2] for quantitative analysis. Conventional solution-based analytical techniques suffer from trivial manipulation, long processing time, and the presence of foreign contaminants. As a result, methods involving direct analysis of solids attract the most attention. In addition to well established X-ray fluorescence (XRF) [3], several MS based methods for the analysis of solids have also been widely used in inorganic analysis, including laser ablation inductively coupled plasma mass spectrometry (LA-ICPMS) [4], glow discharge mass spectrometry (GDMS) [5], secondary ion mass spectrometry (SIMS) [6-9], and laser ionization mass spectrometry (LIMS) [10-16]. Nevertheless, the quantification of the elements present is not enough for sample evaluations because the oxidation state of a particular element may have great influence on the related toxicity, catalytic performance, or refining method. Hence, speciation analysis is often required.

For speciation analysis, both XRF and MS could provide useful information. Using the XRF method, direct speciation could be carried out through investigations of energy shifts or intensity ratios of fluorescence lines [17]. However, these methods are not able to distinguish oxides from salts because the detection of

Address reprint requests to Professor W. Hang, Department of Chemistry, College of Chemistry and Chemical Engineering, Xiamen University, No. 422, Siming South Road, Xiamen, China. E-mail: weihang@xmu.edu.cn line energy, width, or intensity ratios lead to nearly identical results. In contrast, an MS method would not suffer from these problems, as the mass spectrum of binary salts, oxides, and oxysalts could easily be identified. Nevertheless, several obvious faults exist for some MS ionization methods. Conventional GDMS uses sample conductivity and requires analytical grade graphite or metal powder mixtures of insulative oxides [5], which increases the time and cost of sample preparation. Although there are no special requirements for sample properties in SIMS analysis, the limited sputtered ions, pollutants, or the superficial oxide layer, which is stoichiometrically different from the bulk, often make speciation analysis complicated. Thus, before the acquisition of SIMS data, a pre-sputtering step may be necessary.

Due to its versatility, laser ablation is considered a powerful technique in mineral analysis. Currently, the technique is prevalently associated with LA-ICPMS, which has been applied to the elemental and isotopespecific analysis of different types of solid materials [18-20] because of its great experimental flexibility. However, cluster ions, which play key roles for speciation analysis, would not survive in the ICP plasma.

Up to now, several excellent studies have been conducted on oxide differentiation by LIMS. Aubriet et al. evaluated the capabilities of laser ionization Fourier transform mass spectrometry for the speciation of chromium compounds and matrix effects [14]. He also investigated most of the first-row transition-metal oxides and found that a strong correlation between the oxides and the cluster ions exists in both positive and negative ions [21]. Van Vaeck et al. studied the potential and limitations of laser microprobe mass spectrometry (LMMS) for inorganic speciation at a microscopic level 
[22]. By deductive reasoning, compounds from different classes may be identified. Reference spectra were needed for the comparison of compounds with the same elements in different stoichiometries. Hachimi et al. performed speciation of chromium, nickel, and lead compounds in solids with LMMS and applied the technique to environment and biological tissue analysis [16]. Allen et al. [23] described speciation of arsenic oxides using high-mass cluster ions that are unique to the oxidation state of each oxide sample in the negative ion mass spectrum. Maunit et al. distinguished various iron oxides by analyzing the distribution of clusters and explained cluster formation mechanism using LMMS [24, 25]. De Ville d'Avray et al. investigated ferrite nanoparticles by laser desorption ionization mass spectrometry and found that more high $\mathrm{m} / \mathrm{z}$ peaks were produced in $\mathrm{Fe}_{3} \mathrm{O}_{4}$ particles compared with $\mathrm{Fe}_{2} \mathrm{O}_{3}$ [26] However, the above studies were conducted with laser irradiation less than $10^{8} \mathrm{~W} / \mathrm{cm}^{2}$, which indicates that the laser-target interaction mechanism probably involves a desorption-ionization process accompanied by the emission of isolated neutrals, ions, and electrons. For example, ablation-desorption threshold is $4 \times 10^{8}$ and $1 \times 10^{8} \mathrm{~W} / \mathrm{cm}^{2}$ for $\mathrm{V}_{2} \mathrm{O}_{3}$ and $\mathrm{V}_{2} \mathrm{O}_{4}$, respectively [10], and about $5 \times 10^{8} \mathrm{~W} / \mathrm{cm}^{2}$ for $\mathrm{CrO}_{3}, \mathrm{MoO}_{3}$, and $\mathrm{WO}_{3}$ at the wavelength of $355 \mathrm{~nm}$ [27].

Our home-built laser ionization orthogonal time-offlight mass spectrometer (LI-O-TOFMS) has been used in extensive applications, including the direct semiquantitative multi-elemental analysis of solid-state samples such as alloys, ores, biological materials, and residues [28-31]. In this study, we demonstrate the utility of the LI-O-TOFMS for the direct speciation analysis of iron oxides with laser irradiation above $10^{10}$ $\mathrm{W} / \mathrm{cm}^{2}$, leading to a potentially different ionization mechanism compared with the previous studies.

\section{Experimental}

\section{Instrument}

All experiments were performed with an in-house, home-built, laser ionization orthogonal time-of-flight mass spectrometer that had been described previously $[29,31]$. However, several modifications have been made in the source, transmission, and time-of-flight region. A Q-switched Nd:YAG laser (5 ns pulse width, Dawa100, Beamtech Inc., Beijing, China) was used in the experiment. The operating wavelengths were 266, 532 , and $1064 \mathrm{~nm}$. With the use of a single quartz lens, the laser beam was focused onto the sample surface with a focal spot diameter of $50 \mu \mathrm{m}$. To reduce mass discrimination during the transmission, a set of electrical static lenses were employed to replace the hexapole system used previously [31]. Steering plates were added in the TOF region to adjust the trajectory of the ions and increase the sensitivity of the instrument. A digital storage oscilloscope (42Xs, Lecroy, NY, USA) was utilized for spectrum acquisition. Figure 1 and

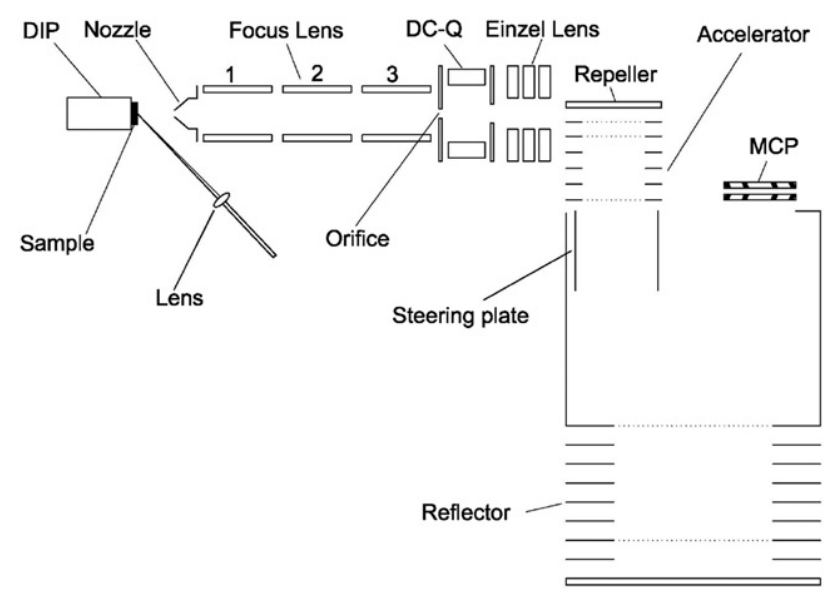

Figure 1. Schematic diagram of the laser ionization orthogonal time-of-flight mass spectrometer.

Table 1 show the schematic diagram of the newly modified system and the operating conditions.

In our previous research related to elemental analysis, buffer gas was introduced to the ion source under mild pressure for ion cooling and charge reduction [32]. However, to obtain information concerning elemental species, little buffer gas should be introduced into the ionization chamber because frequent collisions could lead to spectral complication. Thus, the pressure of the ionization chamber was maintained at the value no more than $200 \mathrm{~Pa}$ throughout the experiment.

\section{Sample Preparation}

The iron oxides investigated in this study included $\mathrm{Fe}_{2} \mathrm{O}_{3}$ and $\mathrm{Fe}_{3} \mathrm{O}_{4}$ (analytical grade, Sinopharm Chemical Reagent Co., Ltd., Shanghai, China). Before being mounted onto the direct insertion probe (DIP), the samples were ground carefully in an agate mortar for 10 min to minimize any effect related to particle size. Next, the samples were pressed in a die under a pressure of $5 \times$ $10^{7} \mathrm{~Pa}$ for $3 \mathrm{~min}$ to produce a disk that was $1.5 \mathrm{~mm}$ in thickness and $8 \mathrm{~mm}$ in diameter. During the experiment, the DIP was mechanically rotated continuously to provide fresh sample surface.

\section{Results and Discussion}

\section{Evaluation of Laser Wavelength}

Iron oxide speciation analysis was performed previously using LMMS with a laser desorption ionization mechanism $[24,25]$. The conclusion was that the neutral species $\mathrm{FeO}$ plays an important role in the formation of various cluster ions. At a wavelength of $586 \mathrm{~nm}(\mathrm{~h} v=$ $2.11 \mathrm{eV}$ ) with laser irradiance of $10^{8} \mathrm{~W} / \mathrm{cm}^{2}, \mathrm{FeO}$ (bond energy $4.23 \mathrm{eV}$ ) can exist, and many large cluster ions appear in the spectrum. When $279 \mathrm{~nm}(4.44 \mathrm{eV})$ and 266 $\mathrm{nm}(4.66 \mathrm{eV})$ wavelengths are used, the energy of the photon exceeds the bond energy of $\mathrm{FeO}$, and the large cluster ions disappear. However, in our work, ion 
Table 1. Summary of the operating parameters of the LI-O-TOFMS system

\begin{tabular}{lc}
\hline Laser & \\
Wavelength & $266,532,1064 \mathrm{~nm}$ \\
Pulse width & $5 \mathrm{~ns}$ \\
Energy & $0.5-10 \mathrm{~mJ}$ \\
Rep. rate & $5 \mathrm{~Hz}$ \\
Spot size & $50 \mu \mathrm{m}$ \\
Transmission system & \\
Nozzle & $37.5 \mathrm{~V}$ \\
Focus lens 1 & $-48 \mathrm{~V}$ \\
Focus lens 2 & $-16 \mathrm{~V}$ \\
Focus lens 3 & $-123 \mathrm{~V}$ \\
Skimmer & $-24 \mathrm{~V}$ \\
DCQ-up & $-5.9 \mathrm{~V}$ \\
DCQ-down & $-3.7 \mathrm{~V}$ \\
DCQ-left & $-6.1 \mathrm{~V}$ \\
DCQ-right & $-2.4 \mathrm{~V}$ \\
Einzel lens-sides & $0 \mathrm{~V}$ \\
Einzel lens-middle & $-18 \mathrm{~V}$ \\
Time-of-Flight & \\
Repelling pulse magnitude & $750 \mathrm{~V}$ \\
Acceleration potential & $-4848 \mathrm{~V}$ \\
Steering plate potential & $-4460 \mathrm{~V}$ \\
\hline
\end{tabular}

abundance distributions were similar at the three wavelengths of $1064 \mathrm{~nm}, 532 \mathrm{~nm}$, and $266 \mathrm{~nm}$. Thus, a different mechanism of ion formation may exist between our work and previous research.

Figure 2 shows the LI-TOFMS spectrum of $\mathrm{Fe}_{2} \mathrm{O}_{3}$ with a laser irradiance of $9.8 \times 10^{10} \mathrm{~W} / \mathrm{cm}^{2}$ at the wavelengths of 1064, 532, and $266 \mathrm{~nm}$. In our study, laser wavelength did not have an obvious impact on the appearance of cluster ions. Comparing the results at laser wavelengths of $532 \mathrm{~nm}(\mathrm{~h} v=2.33 \mathrm{eV})$ and $1064 \mathrm{~nm}$ (hv $=1.17 \mathrm{eV}$ ) (Figure 2a and $\mathrm{b}$, respectively) with that of $266 \mathrm{~nm}$ (Figure 2c), we could find that the detected cluster ions and their distributions were nearly the same. With regard to the explanations, several mechanisms may occur simultaneously. First, thermal effect related to the sublimation of the irradiated solid surface was induced by high irradiance laser ablation. From area in the neighboring of the laser impact, certain stable species (such as iron oxide clusters with the form of $\mathrm{Fe}_{m} \mathrm{O}_{m}[33,34]$ may be ejected in the gas phase. At the same time, a large number of electrons with significant kinetic energy were emitted mainly by thermal effect at high laser irradiance. As a result, part of the cluster ions might be the products from the ionization of neutral species by electrons, which are non-wavelength-dependent [10, 27]. Second, as the laser irradiation in our work was high and reached $9 \times 10^{10} \mathrm{~W} / \mathrm{cm}^{2}$, the central plasma temperature was estimated to be $9 \mathrm{eV}$ at $10 \mathrm{~ns}$ and $4.5 \mathrm{eV}$ at 100 ns after laser radiation [35-37]. Most of the neutral clusters were likely to be dissociated than be ionized at the high temperature (e.g., bond energies for the loss of $\mathrm{O}$ and $\mathrm{O}_{2}$ from iron oxide clusters were between 3 and $5 \mathrm{eV}$ [38], while ionization potentials were 7 to $8 \mathrm{eV}$ for the clusters [39]). As a result, particles at the central part of the expansion plasma

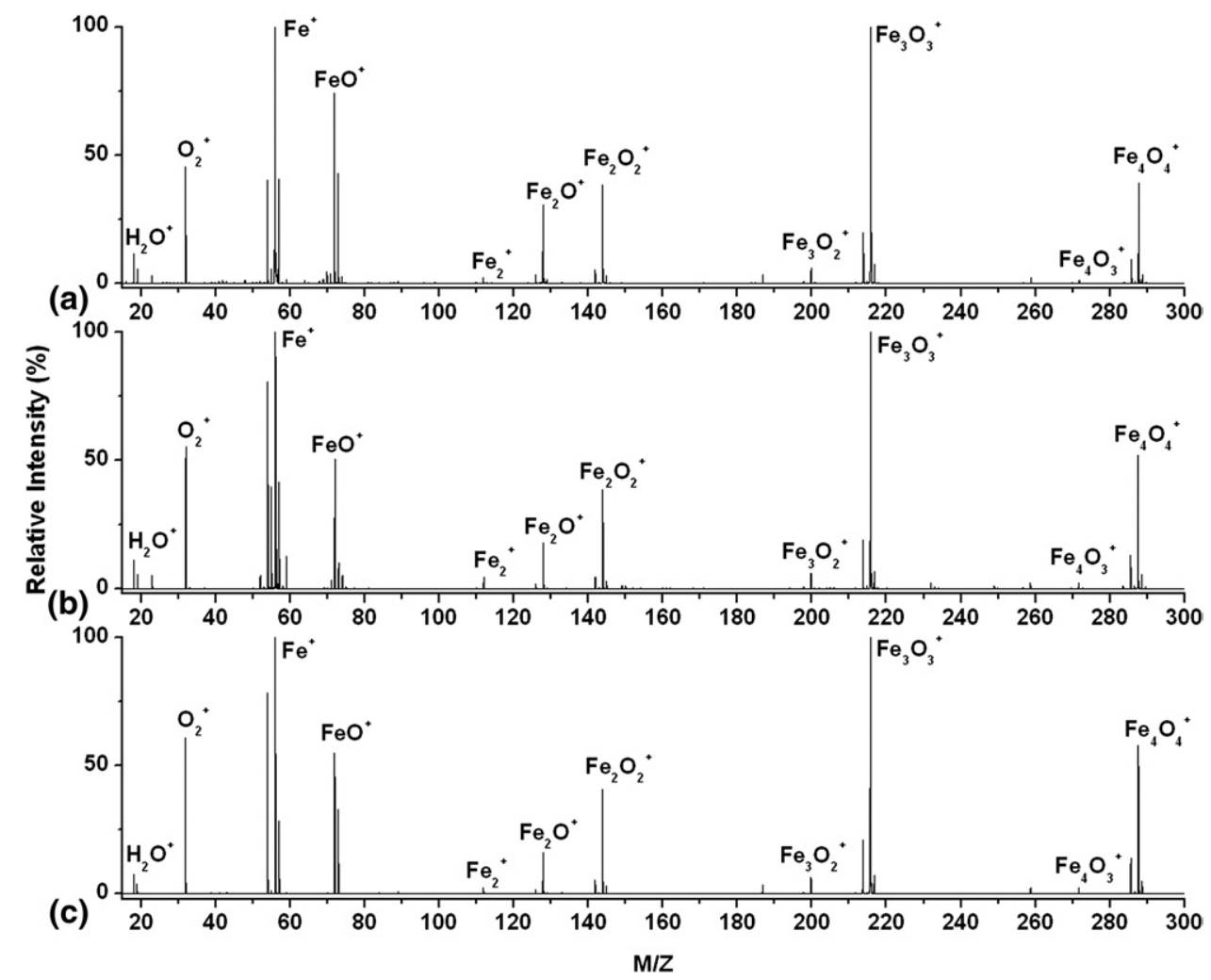

Figure 2. Positive LI-TOFMS spectrum of $\mathrm{Fe}_{2} \mathrm{O}_{3}$ with laser irradiance of $9.8 \times 10^{10} \mathrm{~W} / \mathrm{cm}^{2}$ and wavelengths of (a) 1064, (b) 532, and (c) $266 \mathrm{~nm}$. 
may be fully atomization due to the high temperature, which indicates that part of the neutral FeO comes from the combination of iron and oxygen atoms, and also part of cluster ions are aggregation products after the plasma cools down. We think that the combination and aggregation could be the major pathway for the cluster formation in high laser irradiance. The original sample oxidation state can be revealed from the abundance ratios of the clusters, which could be iron oxide dependant. Thus, the ion formation mechanism in the subsequent discussion is of the primary concern for the differentiation.

\section{Evaluation of Laser Irradiance}

Although the laser irradiance has little effect on the type of ions generated in the plasma, it influences ion intensity and distribution. With no buffer gas introduced, an increase in laser irradiance yielded a rise in the ion intensity, of not only elemental iron, but oxide clusters, as higher laser irradiance would produce more thermal electrons which ionized the neutral species. Besides, signals of cluster ions with large metal portions, e.g., $\mathrm{Fe}_{3} \mathrm{O}_{3}{ }^{+}$and $\mathrm{Fe}_{4} \mathrm{O}_{4}{ }^{+}$, increase noticeably over other cluster ions with an increase in laser irradiance (solid lines in Figure 3). A probable reason for this phenomenon is that higher laser irradiation could promote the endothermic aggregation reaction that leads to the production of large cluster ions with consumption of precursor ions such as $\mathrm{Fe}^{+}$and $\mathrm{FeO}^{+}$. However, as the laser irradiation increased up to $10^{10} \mathrm{~W} / \mathrm{cm}^{2}$, the distribution of ions remained unchanged. This may be due to the limited number of ions that can be sampled by the nozzle. Hence, the laser irradiation used in our speciation analysis was less than $10^{11} \mathrm{~W} / \mathrm{cm}^{2}$.

\section{Evaluation of Buffer Gas Pressure}

The buffer gas pressure determines the mean free path and collision frequency of ions and neutrals in the ionization chamber. In previous work on GDMS [5], a higher pressure yielded higher intensity peaks for elemental ions, while a lower pressure favored the survival of larger clusters. Our studies in LIMS showed similar results (in Figure 4). The intensity of most cluster ions decreased rapidly with an increase in buffer gas pressure, while the signal of $\mathrm{Fe}^{+}$was slightly enhanced. Frequent collisions between cluster ions and buffer gas at high pressure are the cause of the phenomenon described above, in which some cluster ions are dissociated in the collisions. Importantly, with the change in buffer gas pressure, no obvious change was found in the distribution of cluster ions. The proportion of the dissociation of different cluster ions was nearly identical, which is significant because cluster ions, especially their relative ratios, are important for speciation analysis.

The data above show the effects of the wavelength, irradiation, and buffer gas pressure on the signal intensity of elemental and cluster ions for $\mathrm{Fe}_{2} \mathrm{O}_{3}$. The results show that parametric adjustments in the ion source will not change the variety of cluster ions and their relative ratios. Studies of parametric effects were also carried out for $\mathrm{Fe}_{3} \mathrm{O}_{4}$, in which similar trends were found. Due to space constraints, the data are not shown here.

\section{Differentiation of Iron Oxides}

The time-resolved spectra of $\mathrm{Fe}_{2} \mathrm{O}_{3}$ and $\mathrm{Fe}_{3} \mathrm{O}_{4}$ are shown in Figure 5. For both oxides, several $\mathrm{Fe}_{n} \mathrm{O}_{\mathrm{m}}{ }^{+}$

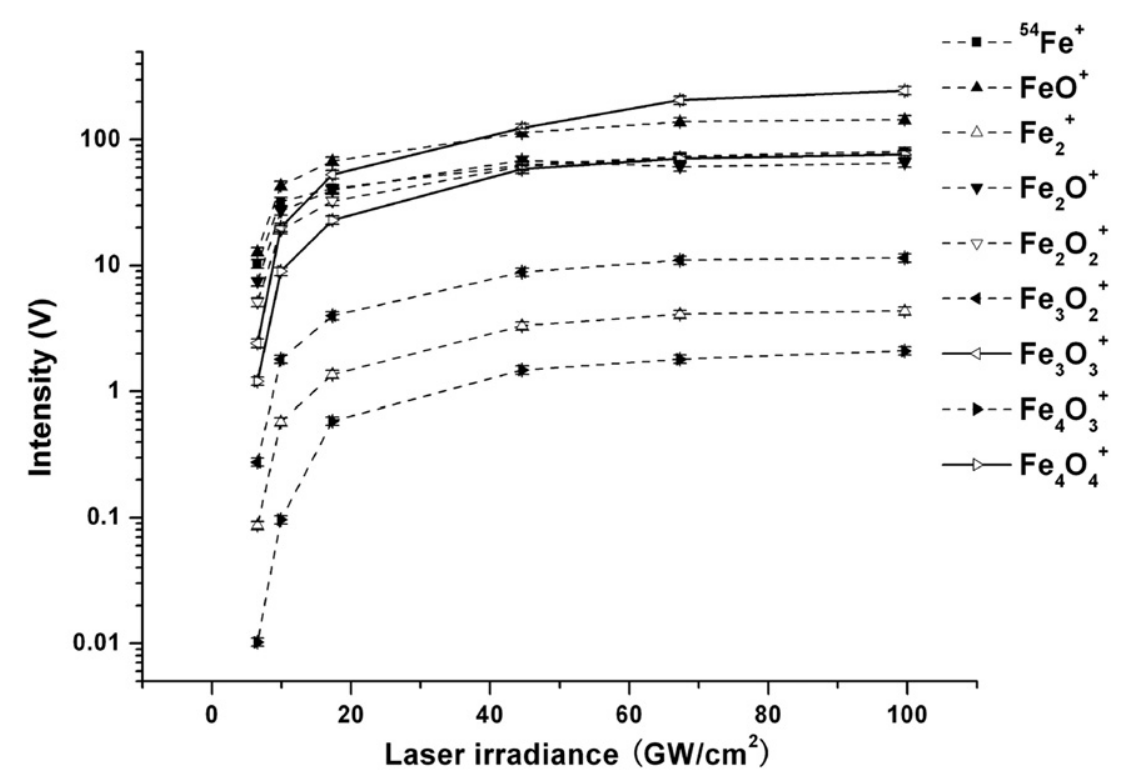

Figure 3. Integrated intensities of the ions as a function of laser irradiance at the $1064 \mathrm{~nm}$ wavelength in the study of $\mathrm{Fe}_{2} \mathrm{O}_{3}$. 


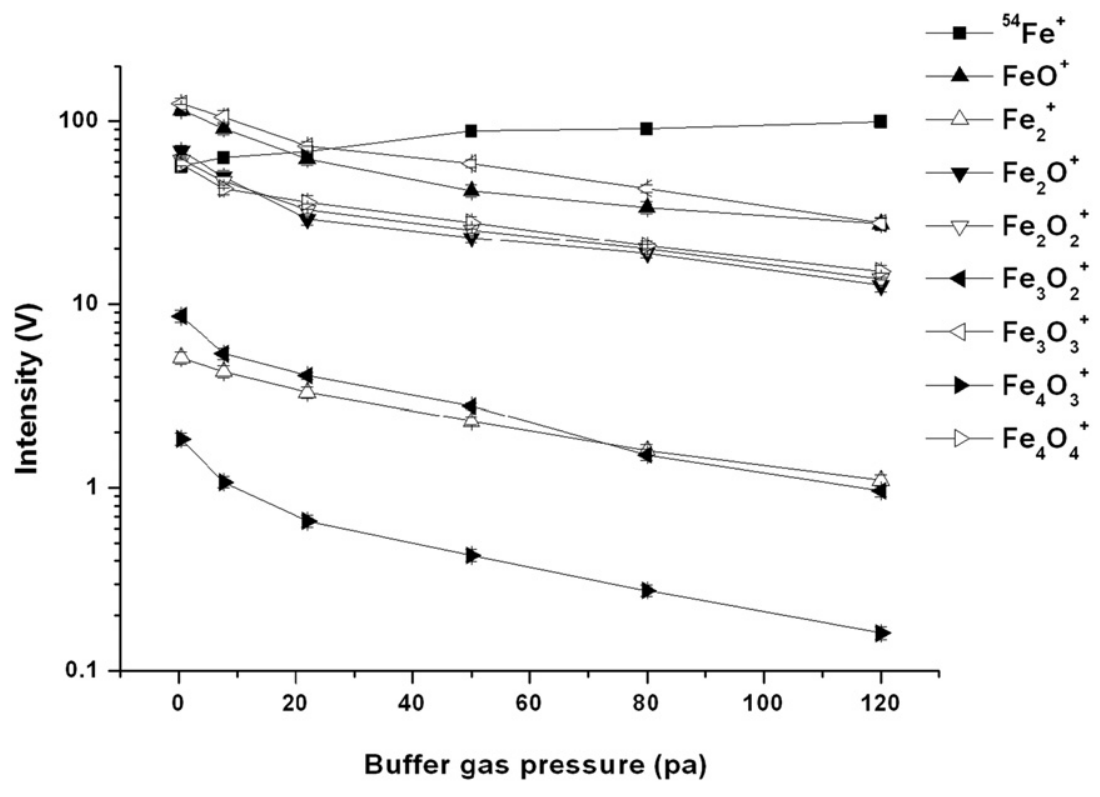

Figure 4. Integrated intensities of the ions as a function of buffer gas pressure with a laser irradiation of $4.5 \times 10^{10} \mathrm{~W} / \mathrm{cm}^{2}$ at a wavelength of $1064 \mathrm{~nm}$ in the study of $\mathrm{Fe}_{2} \mathrm{O}_{3}$.

cluster ions were detected with a similar amount and distribution. No unique peaks could be found for each oxidation state. For ion packets of different ions, dozens of $\mu \mathrm{s}$ are needed to transport the ion from the source through the interface and the electrostatic lenses, to the repelling region. The transport time increased with the $\mathrm{m} / \mathrm{z}$ because of the time-of-flight effect in the transmission system. The duration of an ion packet of identical ions was even shorter, typically of only several $\mu \mathrm{s}$.

The integrated mass spectrum of $\mathrm{Fe}_{2} \mathrm{O}_{3}$ and $\mathrm{Fe}_{3} \mathrm{O}_{4}$ are shown in Figure 6. The relative intensity of cluster ions varies and is dependent on the particular iron oxide. Both of the spectra show strong iron peaks. Cluster ions such as $\mathrm{FeO}^{+}, \mathrm{Fe}_{2} \mathrm{O}_{0-2}{ }^{+}, \mathrm{Fe}_{3} \mathrm{O}_{2,3}{ }^{+}$, and $\mathrm{Fe}_{4} \mathrm{O}_{3,4}{ }^{+}$are also commonly found in our experiment, which is different from previous results where cluster ions containing up to two iron atoms were detected [40-42]. Two important processes could result in the above phenomenon. One is that at high laser irradiance in our experiment, high-energy thermal electrons would ionize the large amount of species (such as $\mathrm{FeO}$, $\mathrm{Fe}_{2} \mathrm{O}_{2}, \mathrm{Fe}_{3} \mathrm{O}_{3}$, and $\mathrm{Fe}_{4} \mathrm{O}_{4}$, etc.) emitted from the neighboring of the laser impact area. Besides, during the expansion of the components, dissociation could occur because of the high collision rate and the residual internal energy remaining in the ions, which may result in the distribution of certain cluster ions, as indicated by Molek et al. [39] that $\mathrm{Fe}_{\mathrm{m}} \mathrm{O}_{\mathrm{m}}{ }^{+}$gradually lose $\mathrm{FeO}$ neutral until $\mathrm{Fe}_{2} \mathrm{O}_{2}{ }^{+}$, followed by $\mathrm{Fe}_{2} \mathrm{O}^{+}$, and ultimately to $\mathrm{Fe}^{+}$. The other reason for the increase in the variety of cluster ions could be the effect of intense aggregation reactions in the plasma under high laser irradiation. As illustrated by Maunit et al. [24, 25], laser irradiation of iron oxides could generate singlet oxygen $\left({ }^{1} \mathrm{O}_{2}\right)$ in the plasma. ${ }^{1} \mathrm{O}_{2}$ plays an important role in the aggregation formation of oxide clusters. Under high laser irradiance, singlet oxygen may still be emitted; part of them is from the neighboring of the laser impacted area where the temperature is high enough for thermal emission but still inadequate for atomization and ionization. The dimer $\mathrm{Fe}_{2}{ }^{+}$was produced by a reaction between $\mathrm{Fe}^{+}$and neutral $\mathrm{FeO}$, while the $\mathrm{Fe}_{2} \mathrm{O}^{+}$ions arise from the reaction of the dimer $\mathrm{Fe}_{2}{ }^{+}$with ${ }^{1} \mathrm{O}_{2}$. However, in our experiment with high laser irradiance, in addition to the mechanism described by Maunit et al., other aggregation pathways may also exist, such as $\mathrm{Fe}^{+}+\mathrm{O}_{2} \rightarrow \mathrm{FeO}^{+}+\mathrm{O}, \mathrm{Fe}^{+}+\mathrm{FeO} \rightarrow \mathrm{Fe}_{2} \mathrm{O}^{+}$, $\mathrm{Fe}_{\mathrm{n}} \mathrm{O}_{\mathrm{n}}{ }^{+}+\mathrm{FeO} \rightarrow \mathrm{Fe}_{\mathrm{m}} \mathrm{O}_{\mathrm{m}}{ }^{+}(n=1,2,3, \mathrm{~m}=n+1)$, $\mathrm{Fe}_{\mathrm{n}} \mathrm{O}_{\mathrm{n}-1}{ }^{+}+\mathrm{FeO} \rightarrow \mathrm{Fe}_{\mathrm{m}} \mathrm{O}_{\mathrm{m}-1}{ }^{+}(n=2,3, \mathrm{~m}=n+1)$. Therefore, possibly part of the large cluster ions were from a complex aggregation reaction. Besides, as indicated by Molek [39], species in the form of $(\mathrm{FeO})_{n}{ }^{+}$have the greatest stability of iron oxide clusters, which explains why $\mathrm{Fe}_{3} \mathrm{O}_{3}^{+}$and $\mathrm{Fe}_{4} \mathrm{O}_{4}{ }^{+}$showed strong ion peaks in our spectra for both iron oxides. It should be noted that $\mathrm{O}_{2}{ }^{+}$peaks could be seen, while $\mathrm{O}^{+}$peaks were barely observed (Figure 6). This does not reflect the amount of emitted oxygen due to the relatively low ionization energy $(\mathrm{IE})$ of $\mathrm{O}_{2}(\mathrm{IE}=12.07 \mathrm{eV})$ compared with that of $\mathrm{O}(\mathrm{IE}=13.62 \mathrm{eV})$.

The differentiation of the two oxides was performed on the basis of abundance ratios of clusters. Specifically, the abundance ratios of two ion species in the same series (i.e., with the same number of iron atoms) are often a criterion of choice for speciation $[8,21]$. These ratios are reported in Figure 7. For the ratio of $\mathrm{Fe}_{2}{ }^{+}$to $\mathrm{Fe}_{2} \mathrm{O}^{+}$, relatively higher abundances of the $\mathrm{Fe}_{2}{ }^{+}$ion are indicative of $\mathrm{Fe}_{3} \mathrm{O}_{4}$, which is expected and consistent with previously published results [24, 25]. Judging from the iron and oxygen content from the molecular formula of $\mathrm{Fe}_{2} \mathrm{O}_{3}$ and $\mathrm{Fe}_{3} \mathrm{O}_{4}$, one could predict that the ion 

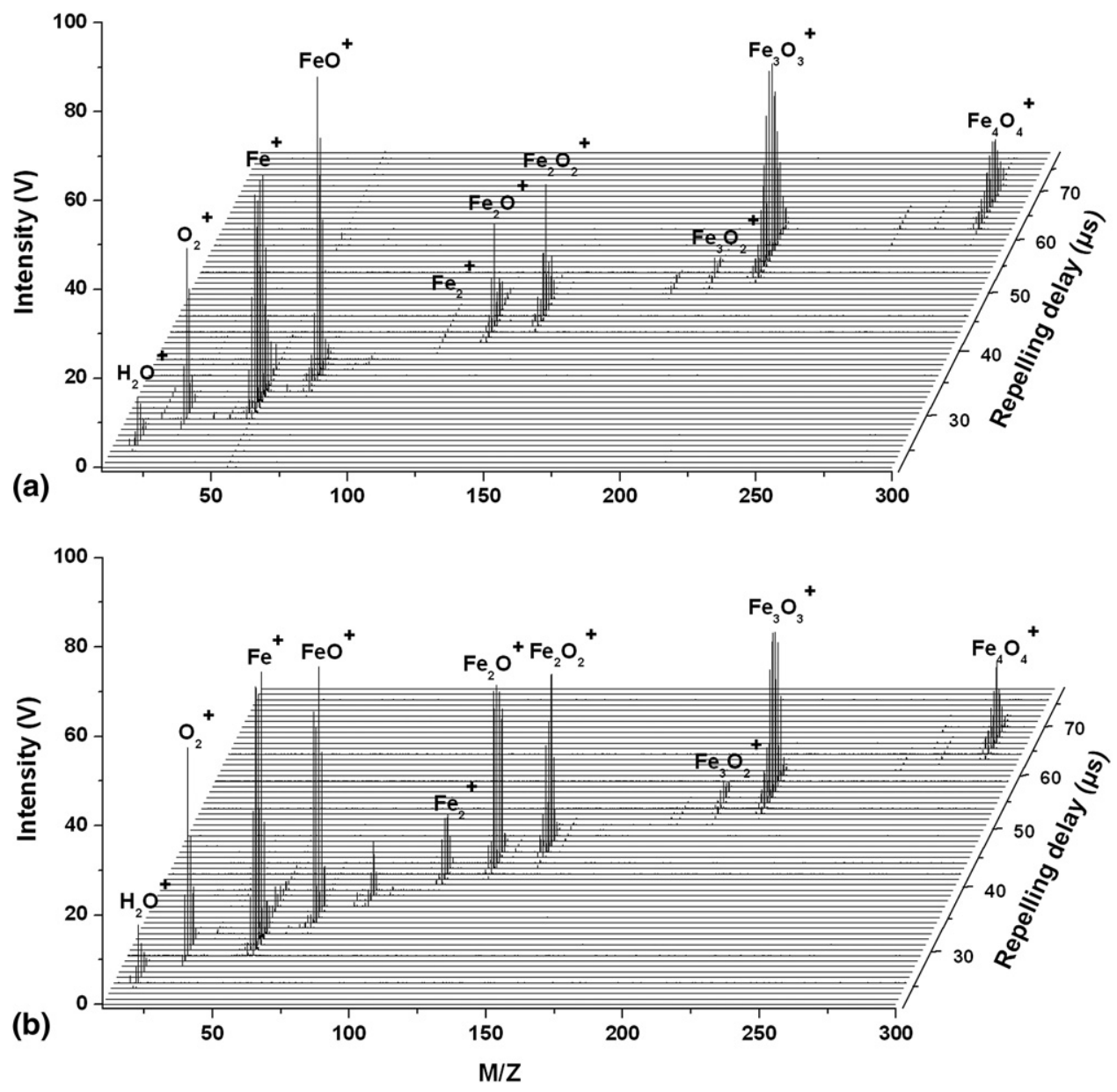

Figure 5. Time resolved mass spectra of (a) $\mathrm{Fe}_{2} \mathrm{O}_{3}$ and (b) $\mathrm{Fe}_{3} \mathrm{O}_{4}$ as a function of time after laser ionization with laser irradiance of $9.8 \times 10^{10} \mathrm{~W} / \mathrm{cm}^{2}$ at the $1064 \mathrm{~nm}$ wavelength.

ratio of $\mathrm{Fe}_{2}^{+}$to $\mathrm{Fe}_{2} \mathrm{O}^{+}$in the two samples might be close. However, the results in our research did not match this prediction as the ratio in the two samples was significantly different. This was not surprising, as several formation mechanisms of $\mathrm{Fe}_{2} \mathrm{O}^{+}$might exist: electron ionization of neutral species, dissociation from large cluster ions, and combination and aggregation approaches. Hence, one probable reason for the obvious difference in the ratio of $\mathrm{Fe}_{2}{ }^{+}$to $\mathrm{Fe}_{2} \mathrm{O}^{+}$was due to the varying amounts of emitted oxygen during laser ablation of the two oxides and the fact that it is easier to produce ${ }^{1} \mathrm{O}_{2}$ from $\mathrm{Fe}_{2} \mathrm{O}_{3}$ during laser ablation than $\mathrm{Fe}_{3} \mathrm{O}_{4}$. According to past studies, the singlet oxygen came from the bulk structures of the samples. The thermo-emission activity of ${ }^{1} \mathrm{O}_{2}$ is inversely proportional to the specific surface area (SPA, which measures the total surface area per unit of mass) of investigated samples [43, 44], because large SPA inhibits the emission of ${ }^{1} \mathrm{O}_{2}$ from the volume localization. To verify the singlet oxygen emission from the oxides, an experiment was conducted to measure the SPA with a surface area analyzer (TriStar II 3020; Micromeritics, Norcross, GA, USA). The measured values were 4.69 and $8.21 \mathrm{~cm}^{2} / \mathrm{g}$ for $\mathrm{Fe}_{2} \mathrm{O}_{3}$ and $\mathrm{Fe}_{3} \mathrm{O}_{4}$, respectively, which proves that a larger amount of singlet oxygen was emitted from $\mathrm{Fe}_{2} \mathrm{O}_{3}$ than $\mathrm{Fe}_{3} \mathrm{O}_{4}$.

The same iron oxides were also analyzed by a laser desorption ionization mass spectrometer (MicroFlex MALDI-TOFMS, with a laser wavelength of $337 \mathrm{~nm}$, Bruker, Bremen, Germany). The sample plate was modified such that the oxides, with no matrix added, could be held in the cavities on the plate. Averaged spectra were acquired with the average of 100 single spectra, comparative to the accumulated spectra of 100 single spectra in Figure 6 at high irradiance. Peaks can be observed steadily in a narrow irradiance range of $1.70-1.82 \times 10^{8} \mathrm{~W} / \mathrm{cm}^{2}$. With the irradiance below $1.70 \times$ $10^{8} \mathrm{~W} / \mathrm{cm}^{2}$, the signals were too weak to be observed, while the background went high and the resolution became extremely poor with the irradiance beyond $1.82 \times$ $10^{8} \mathrm{~W} / \mathrm{cm}^{2}$. The highest mass peak that appeared stably was $\mathrm{Fe}_{2} \mathrm{O}_{2}{ }^{+}$. The ratios of $\mathrm{Fe}_{2}{ }^{+} / \mathrm{Fe}_{2} \mathrm{O}^{+}$and $\mathrm{Fe}_{2} \mathrm{O}^{+} / \mathrm{Fe}_{2} \mathrm{O}_{2}{ }^{+}$are plotted in Figure 7 (dashed line bar, with irradiance of $1.75 \times 10^{8} \mathrm{~W} / \mathrm{cm}^{2}$ ). Their RSDs are about $20 \%$.

Therefore, in low irradiance $\left(\leq 10^{8} \mathrm{~W} / \mathrm{cm}^{2}\right)$ LIMS, spectrum is wavelength related $[24,25]$, the speciation of iron oxides usually depends on the ratios of $\mathrm{Fe}_{2}{ }^{+} /$ 


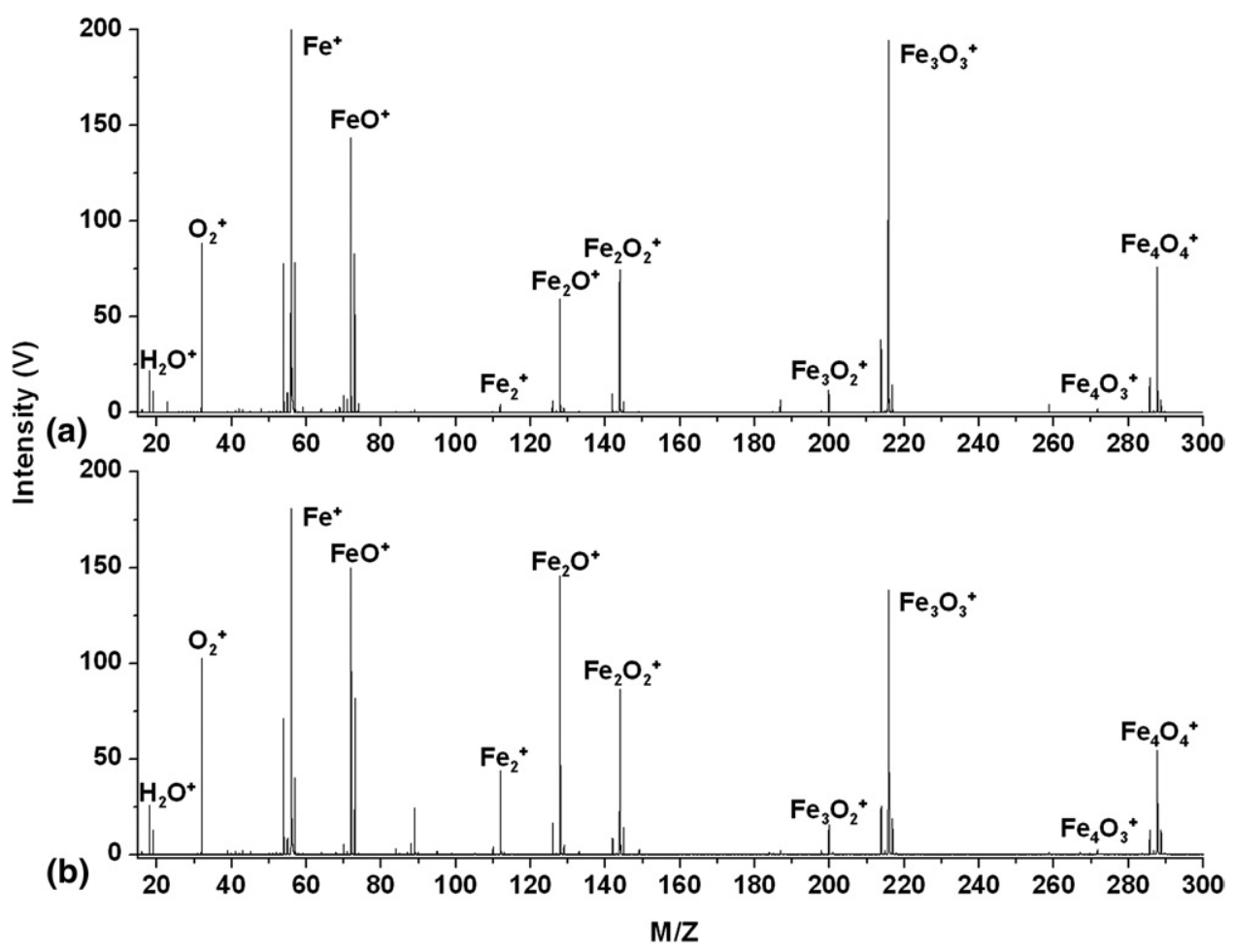

Figure 6. Integrated spectra of (a) $\mathrm{Fe}_{2} \mathrm{O}_{3}$ and (b) $\mathrm{Fe}_{3} \mathrm{O}_{4}$ from LI-O-TOFMS with laser irradiance of $9.8 \times 10^{10} \mathrm{~W} / \mathrm{cm}^{2}$ at the wavelength of $1064 \mathrm{~nm}$.

$\mathrm{Fe}_{2} \mathrm{O}^{+}$and $\mathrm{Fe}_{2} \mathrm{O}^{+} / \mathrm{Fe}_{2} \mathrm{O}_{2}{ }^{+}$. At high irradiance $\left(\geq 10^{9}\right.$ $\mathrm{W} / \mathrm{cm}^{2}$ ) LIMS, high-resolution spectra can be obtained with orthogonal geometry TOF analyzer; the ratios of $\mathrm{Fe}_{3} \mathrm{O}_{2}{ }^{+} / \mathrm{Fe}_{3} \mathrm{O}_{3}{ }^{+}$and $\mathrm{Fe}_{4} \mathrm{O}_{3}{ }^{+} / \mathrm{Fe}_{4} \mathrm{O}_{4}{ }^{+}$can be added (as shown in Figure 7), which is independent of wavelength and further validates the speciation. Moreover, the cluster distribution under low irradiance relies heavily on the neutral $\mathrm{FeO} ; \mathrm{FeO}$ is directly generated through laser desorption, which is sensitive to the

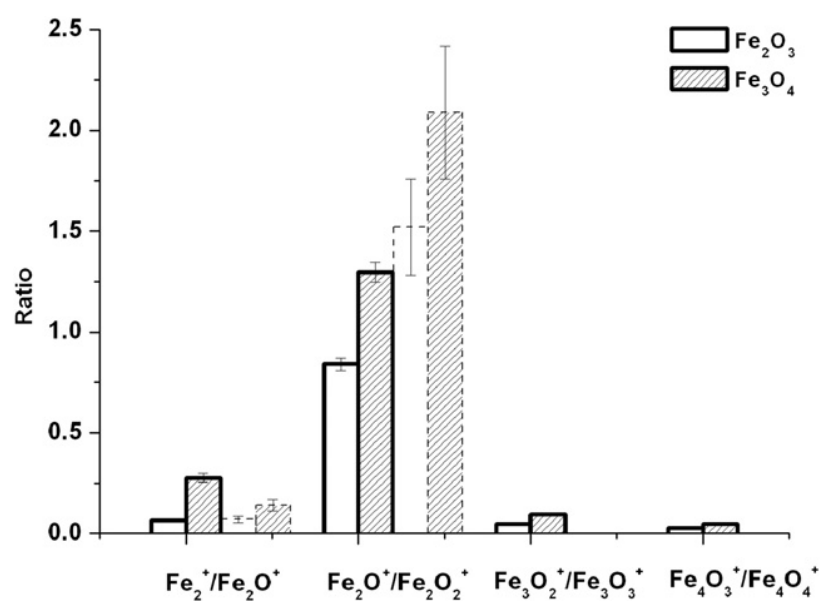

Figure 7. The ratios between the peak intensity of $\mathrm{Fe}_{2}{ }^{+} / \mathrm{Fe}_{2} \mathrm{O}^{+}$, $\mathrm{Fe}_{2} \mathrm{O}^{+} / \mathrm{Fe}_{2} \mathrm{O}_{2}{ }^{+}, \mathrm{Fe}_{3} \mathrm{O}_{2}{ }^{+} / \mathrm{Fe}_{3} \mathrm{O}_{3}{ }^{+}$, and $\mathrm{Fe}_{4} \mathrm{O}_{3}{ }^{+} / \mathrm{Fe}_{4} \mathrm{O}_{4}{ }^{+}$for $\mathrm{Fe}_{2} \mathrm{O}_{3}$, and $\mathrm{Fe}_{3} \mathrm{O}_{4}$. Solid line bars are for high irradiance of $9.8 \times 10^{10}$ $\mathrm{W} / \mathrm{cm}^{2}$ at the wavelength of $1064 \mathrm{~nm}$ using LI-O-TOFMS; dash line bars for low irradiance of $1.75 \times 10^{8} \mathrm{~W} / \mathrm{cm}^{2}$ at the wavelength of $337 \mathrm{~nm}$ using MALDI-TOFMS. parametric change, such as the fluctuation of laser flux. In high irradiance LIMS, apart from electron ionization of ablated neutral species, clusters were also formed by aggregation from the atomized iron oxides when the plasma cools down. As shown in Figure 7, the ratios are stable with an RSD of about $7 \%$.

\section{Conclusion}

High irradiance laser ionization time-of-flight mass spectrometry has been investigated in the direct speciation analysis of iron oxides. A vacuum laser ionization source can effectively reduce the dissociation process and keep the mass spectrum simple. Ion peaks can be identified according to their $\mathrm{m} / \mathrm{z}$ values and separated by the delay time between the laser pulse and repelling pulse. With only iron, oxygen, and their clusters shown in the spectra, the samples can easily be identified as iron oxides. The clusters formed at high irradiance could be the combination of several mechanisms: electron ionization of neutral species, dissociation from large cluster ions, and aggregation reactions. The ion abundance ratios of the clusters with the same number of iron atoms can be used for the speciation of iron oxides, while, other than using the ratios of small cluster ions, the ratios of $\mathrm{Fe}_{3} \mathrm{O}_{2}{ }^{+} / \mathrm{Fe}_{3} \mathrm{O}_{3}{ }^{+}$, and $\mathrm{Fe}_{4} \mathrm{O}_{3}{ }^{+} /$ $\mathrm{Fe}_{4} \mathrm{O}_{4}{ }^{+}$, can also be used for speciation with high laser irradiance. Unlike the laser desorption technique, stable ratios of the ion species can be obtained under high irradiance for the direct speciation of iron oxides, pos- 
sibly due to involvement of the atomization and aggregation mechanisms.

\section{Acknowledgments}

The authors gratefully acknowledge financial support from National 863 Program, the Natural Science Foundation of China, and Fujian Province Department of Science and Technology.

\section{References}

1. Al-Harahsheh, M.; Kingman, S.; Somerfield, C.; Ababneh, F. MicrowaveAssisted Total Digestion of Sulphide Ores for Multi-Element Analysis. Anal. Chim. Acta 2009, 638(1), 101-105.

2. Qi, L.; Zhou, M.-F.; Wang, C. Y. Determination of low Concentrations of Platinum Group Elements in Geological Samples by ID-ICP-MS. J. Anal. At. Spectrom. 2004, 19(10), 1335-1339.

3. Sitko, R.; Zawisza, B.; Krzykawski, T.; Malicka, E. Determination of Chemical Composition of Siderite in Concretions by WavelengthDispersive X-Ray Spectrometry Following Selective Dissolution. Talanta 2009, 77(3), 1105-1110.

4. Cottle, J. M.; Horstwood, M. S. A.; Parrish, R. R. A New Approach to Single Shot Laser Ablation Analysis and Its Application to In Situ Pb/U Geochronology. J. Anal. At. Spectrom. 2009, 24(10), 1355-1363.

5. Robertson-Honecker, J. N.; Zhang, N.; Pavkovich, A.; King, F. L. Direct Chromium Speciation in Solid State Materials-a GDMS Approach. J. Anal. At. Spectrom. 2008, 23(11), 1508-1517.

6. Van Ham, R.; Van Vaeck, L.; Adriaens, A.; Adams, F.; Hodges, B.; Appelhans, A.; Groenewold, G. Semiquantitative Characterization of Binary Salt Mixtures with Static Secondary Ion Mass Spectrometry (S-SIMS). Int. J. Mass Spectrom. 2005, 247(1/3), 28-36.

7. Van Ham, R.; Van Vaeck, L.; Adams, F. C.; Adriaens, A. Systematization of the Mass Spectra for Speciation of Inorganic Salts with Static Secondary Ion Mass Spectrometry. Anal. Chem. 2004, 76(9), 2609-2617.

8. Aubriet, F.; Poleunis, C.; Bertrand, P. Capabilities of static TOF-SIMS in the differentiation of first-row transition metal oxides. J. Mass Spectrom. 2001, 36(6), 641-651.

9. Van Ham, R.; Adriaens, A.; Van Vaeck, L.; Gijbels, R.; Adams, F. Molecular Information in Static SIMS for the Speciation of Inorganic Compounds. Nuclear Instrum. Methods Phys. Res. B 2000, 161/163, 245-249.

10. Aubriet, F.; Muller, J.-F. Laser Ablation Mass Spectrometry of Inorganic Transition Metal Compounds. Additional Knowledge for the Understanding of Ion Formation. J. Am. Soc. Mass Spectrom. 2008, 19(4), $488-501$.

11. Gunther, D.; Hattendorf, B. Solid Sample Analysis Using Laser Ablation Inductively Coupled Plasma Mass Spectrometry. Trends Anal. Chem. 2005, 24(3), 255-265

12. Klunder, G. L.; Grant, P. M.; Andresen, B. D.; Russo, R. E. Direct Chemical Analysis of Solids by Laser Ablation in an Ion Storage Time-of-Flight Mass Spectrometer. Anal. Chem. 2004, 76(5), 1249-1256.

13. Ignatova, V.; Van Vaeck, L.; Gijbels, R.; Adams, F. Molecular Speciation of Inorganic Mixtures by Fourier Transform Laser Microprobe Mass Spectrometry. Int. J. Mass Spectrom. 2003, 225(3), 213-224.

14. Aubriet, F.; Maunit, B.; Muller, J.-F. Speciation of Chromium Compounds by Laser Ablation/Ionization Mass Spectrometry and a Study of Matrix Effects. Int. J. Mass Spectrom. 2001, 209(1), 5-21.

15. Poels, K.; Van Vaeck, L.; Gijbels, R. Microprobe Speciation Analysis of Inorganic Solids by Fourier Transform Laser Mass Spectrometry. Anal. Chem. 1998, 70(3), 504-512.

16. Hachimi, A.; Van Vaeck, L.; Poels, K.; Adams, F.; Muller, J. F. Speciation of Chromium, Lead, and Nickel Compounds by Laser Microprobe Mass Spectrometry and Application to Environmental and Biological Samples. Spectrochim. Acta B 1998, 53(2), 347-365.

17. Torres Deluigi, M.; Tirao, G.; Stutz, G.; Cusatis, C.; Riveros, J. A. Dependence with the Oxidation State of X-Ray Transition Energies, Intensities, and Natural Line Widths of CrK $\beta$ Spectra. Chem. Phys. 2006, 325(2/3), 477-484

18. Jochum, K. P.; Stoll, B.; Herwig, K.; Amini, M.; Abouchami, W.; Hofmann, A. W. Lead Isotope Ratio Measurements in Geological Glasses by Laser Ablation-Sector Field-ICP Mass Spectrometry (LA-SF-ICPMS). Int. J. Mass Spectrom. 2005, 242(2/3), 281-289.

19. Leach, A. M.; Hieftje, G. M. Standardless Semiquantitative Analysis of Metals Using Single-Shot Laser Ablation Inductively Coupled Plasma Time-of-Flight Mass Spectrometry. Anal. Chem. 2001, 73(13), 2959-2967.

20. Tanner, M.; Günther, D. A New ICP-TOFMS. Measurement and Readout of Mass Spectra with $30 \mu$ s Time Resolution, Applied to In-Torch LA-ICP-MS. Anal. Bioanal. Chem. 2008, 391(4), 1211-1220.
21. Aubriet, F.; Poleunis, C.; Muller, J.-F.; Bertrand, P. Laser Ablation and Secondary Ion Mass Spectrometry of Inorganic Transition-Metal Compounds. Part I: Comparison Between Static TOF-SIMS and LA-FTICRMS. J. Mass Spectrom. 2006, 41(4), 527-542.

22. Van Vaeck, L.; Adriaens, A.; Adams, F. Microscopical Speciation Analysis with Laser Microprobe Mass Spectrometry and Static Secondary Ion Mass Spectrometry. Spectrochim. Acta B 1998, 53(2), 367-378.

23. Allen, T. M.; Bezabeh, D. Z.; Smith, C. H.; McCauley, E. M.; Jones, A. D.; Chang, D. P. Y.; Kennedy, I. M.; Kelly, P. B. Speciation of Arsenic Oxides Using Laser Desorption/Ionization Time-of-Flight Mass Spectrometry. Anal. Chem. 1996, 68(22), 4052-4059.

24. Maunit, B.; Hachimi, A.; Manuelli, P.; Calba, P. J.; Muller, J. F. Formation of Iron Oxides Clusters Induced by Resonant Laser Ablation/ Ionization. Int. J. Mass Spectrom. Ion Processes 1996, 156(3), 173-187.

25. Maunit, B.; Hachimi, A.; Calba, P. J.; Krier, G.; Muller, J. F. A New Method for the Determination of Iron Oxidation States by Resonant and Non-Resonant Ionization Mass Spectrometry. Rapid Commun. Mass Spectrom. 1995, 9(3), 225-229.

26. De Ville d'Avray, A. T.; Carpenter, E. E.; O'Connor, C. J.; Cole, R. B. Characterization of Ferrite Nanoparticles by Laser Desorption/Ionization Mass Spectrometry. Eur. J. Mass Spectrom. 1998, 4(6), 441-449.

27. Aubriet, F.; Muller, J.-F. About the Atypical Behavior of $\mathrm{CrO} 3, \mathrm{MoO} 3$ and WO3 During Their UV Laser Ablation/Ionization. J. Phys. Chem. A 2002, 106(25), 6053-6059

28. Chen, L.; Lin, L.; Yu, Q.; Yan, X.; Hang, W.; He, J.; Huang, B. Semiquantitative Multi-Elemental Analysis of Biological Samples by a Laser Ionization Orthogonal Time-of-Flight Mass Spectrometer. J. Am. Soc. Mass Spectrom. 2009, 20(7), 1355-1358.

29. Peng, D.; He, J.; Yu, Q.; Chen, L.; Hang, W.; Huang, B. Parametric Evaluation of Laser Ablation and Ionization Time-of-Flight Mass Spectrometry with Ion Guide Cooling Cell. Spectrochim. Acta B 2008, 63(8), $868-874$.

30. Yu, Q.; Cao, Z.; Li, L.; Yan, B.; Hang, W.; He, J.; Huang, B. Femtogram Detection and Quantitation of Residues Using Laser Ionization Orthogonal Time-of-Flight Mass Spectrometry. Anal. Chem. (Washington, DC) 2009, 81(20), 8623-8626.

31. Tong, Q.; Yu, Q.; Jin, X.; He, J.; Hang, W.; Huang, B. Semiquantitative Analysis of Geological Samples Using Laser Plasma Time-of-Flight Mass Spectrometry. J. Anal. At. Spectrom. 2009, 24(2), 228-231.

32. Yu, Q.; Huang, R.; Li, L.; Lin, L.; Hang, W.; He, J.; Huang, B. Applicability of Standardless Semiquantitative Analysis of Solids by High-Irradiance Laser Ionization Orthogonal Time-of-Fight Mass Spectrometry. Anal. Chem. 2009, 81(11), 4343-4348.

33. Shin, D. N.; Matsuda, Y.; Bernstein, E. R. On the Iron Oxide Neutral Cluster Distribution in the Gas Phase. I. Detection Through $193 \mathrm{~nm}$ Multiphoton Ionization. J. Chem. Phys. 2004, 120(9), 4150-4156.

34. Shin, D. N.; Matsuda, Y.; Bernstein, E. R. On the Iron Oxide Neutral Cluster Distribution in the Gas Phase. II. Detection Through $118 \mathrm{~nm}$ Single Photon Ionization. J. Chem. Phys. 2004, 120(9), 4157-4163.

35. Harilal, S. S.; Bindhu, C. V.; Issac, R. C.; Nampoori, V. P. N.; Vallabhan, C. P. G. Electron Density and Temperature Measurements in a Laser Produced Carbon Plasma. J. Appl. Phys. 1997, 82(5), 2140-2146.

36. Cowpe, J. S.; Pilkington, R. D.; Astin, J. S.; Hill, A. E. The Effect of Ambient Pressure on Laser-Induced Silicon Plasma Temperature, Density, and Morphology. J. Phys. D Appl. Phys. 2009, 42(16), 165202/1$165202 / 8$.

37. Bogaerts, A.; Chen, Z.; Bleiner, D. Laser Ablation of Copper in Different Background Gases: Comparative Study by Numerical Modeling and Experiments. J. Anal. At. Spectrom. 2006, 21(4), 384-395.

38. Li, M.; Liu, S.-R.; Armentrout, P. B. Collision-Induced Dissociation Studies of FemOn +: Bond Energies in Small Iron Oxide Cluster Cations, FemOn $+(\mathrm{m}=1-3, \mathrm{n}=1-6)$. J. Chem. Phys. 2009, 131(14), 144310/ $1-144310 / 16$.

39. Molek, K. S.; Anfuso-Cleary, C.; Duncan, M. A. Photodissociation of Iron Oxide Cluster Cations. J. Phys. Chem. A 2008, 112(39), 9238-9247.

40. Gallavardin, S.; Lohmann, U.; Cziczo, D. Analysis and Differentiation of Mineral Dust by Single Particle Laser Mass Spectrometry. Int. J. Mass Spectrom. 2008, 274(1/3), 56-63.

41. Held, A.; Hinz, K. P.; Trimborn, A.; Spengler, B.; Klemm, O. Chemical Classes of Atmospheric Aerosol Particles at a Rural Site in Central Europe During Winter. J. Aerosol Sci. 2002, 33(4), 581-594.

42. Hinz, K.-P.; Trimborn, A.; Weingartner, E.; Henning, S.; Baltensperger, U.; Spengler, B. Aerosol Single Particle Composition at the Jungfraujoch. J. Aerosol Sci. 2005, 36(1), 123-145.

43. Kopylov, V. B.; Aleksandrov, K. A.; Sergeev, E. V. Thermal Evolution of the Chemical Structure and Properties of Silicon Oxides. Russ. J. Gen. Chem. 2008, 78(5), 868-875.

44. Kopylov, V. B.; Sergeev, E. V. Thermo-Emission of Singlet Oxygen and Chemical Structure of Copper Oxides. Russ. J. Gen. Chem. 2008, 78(6), 1111-1117. 